\title{
Knowledge of asthma management by general practitioners in Karachi, Pakistan: comparison with international guidelines
}

\author{
*Nizar Bhulania, Saima Lalania, Aziez Ahmeda, Yahya Jana, Urooba Faheemª, Ayub Khan, \\ Zahra Samani ${ }^{a}$, Wahaj Aman $^{a}$, Faria Bhattia, Omar Hayat ${ }^{a}$, Sarah Saleem $^{\mathrm{b}}$
}

${ }^{a}$ Medical College, Aga Khan University, Karachi, Pakistan

${ }^{\mathrm{b}}$ Associate Professor, Department of Community Health Sciences, Aga Khan University, Karachi, Pakistan

Received 28th April 2011; resubmitted 5th August 2011; revised 12th September 2011; accepted 18th September 2011; online 15th November 2011

\begin{abstract}
Background: Suboptimal management of asthma by general practitioners (GPs) can lead to poor health outcomes

Aims: To assess the management of common asthma presentations by GPs using the Global Initiative for Asthma (GINA) guidelines as a comparative tool.

Methods: A cross-sectional survey was conducted in Karachi, Pakistan. Of 250 GPs approached, 192 completed a self-administered questionnaire regarding pathology, key history points, risk factors, diagnosis, and management of asthma.

Results: Overall, $28.6 \%$ of GPs had adequate knowledge of the core concepts of asthma, while only $10.4 \%$ had adequate practice in asthma management. About $78 \%$ of GPs had inadequate knowledge of pathology, about $90 \%$ had inadequate knowledge of medications to be used, and $63 \%$ had inadequate knowledge regarding diet restrictions. Knowledge regarding symptoms not usually associated with asthma was adequate, as was knowledge regarding non-pharmacological management (79\% each). Practices regarding asthma diagnosis were good (99.0\%). However, practices regarding acute exacerbations and patients who wish to exercise were inadequate in $85.9 \%$ and $82.8 \%$ of GPs, respectively.
\end{abstract}

Conclusions: The majority of GPs had poor knowledge and practice of asthma. We recommend initiation of programmes to improve their knowledge and practices.

(C) 2011 Primary Care Respiratory Society UK. All rights reserved.

N Bhulani et al. Prim Care Respir J 2011; 20(4): 448-451

http://dx.doi.org/10.4104/pcrj.2011.00096

Keywords asthma, knowledge, management, guidelines, general practitioners, Karachi (Pakistan)

\section{Introduction}

Asthma is a common reversible inflammatory condition of the lungs that leads to narrowing of the bronchi. It has several characteristic features including wheezing, breathlessness, chest tightness, and coughing. ${ }^{1}$ According to the World Health Organization (WHO), almost 300 million people suffer from asthma worldwide. ${ }^{2}$ The prevalence is continuously rising and is expected to rise by a further 100 million by the year $2025 .{ }^{3}$ It is estimated that nearly 255,000 people died globally from asthma in $2005 .{ }^{2}$ Almost $80 \%$ of asthma-related deaths occur in low and lower middle income countries, ${ }^{2}$ and nearly 50 million people with asthma are known to reside in Southern and Central Asia. ${ }^{3} \mathrm{~A}$ family history of asthma together with environmental exposures such as tobacco smoke, dust mites, outdoor air pollution, pets, and mould are considered important triggers of an asthma attack. ${ }^{3}$ When treated ineffectively, asthma often leads to hospitalisation, missed work and school, limited physical activity, sleepless nights, and in some cases it may even cause death.

Various local and international studies have been performed to assess the knowledge and practices of general practitioners (GPs) with regard to asthma management, and have shown that GPs have inadequate knowledge of asthma itself and its management. ${ }^{4-6}$

The Global Initiative for Asthma (GINA) guidelines were launched in 1993 with the involvement of WHO to produce a

\footnotetext{
* Corresponding author: Mr Nizar Bhulani, The Aga Khan University, Stadium Road, PO Box 3500, Karachi 74800, Pakistan.

Tel: +92-333-3013898 E-mail: nizar.bhulani@gmail.com
} 
consensus on asthma treatment. The GINA guidelines provide the foundation for several asthma guidelines worldwide and are regularly updated. The aim of this study was to assess GPs' knowledge of the pathology, typical history, associated risk factors, familiarity with various medications for the treatment of asthma, diagnosis of asthma, and their management practices in predefined real-life case presentations. We also compared the practices of GPs with international standards of management of asthma (i.e. the GINA guidelines).

\section{Methods}

A cross-sectional survey was conducted between February and April 2010 among GPs in Karachi, Pakistan. A list of GPs was obtained from the Department of Community Health Sciences, Aga Khan University, Pakistan, which had been prepared for previous studies. A total of 250 GPs were identified from various areas of Karachi. Interviews were conducted by Year 4 medical students of Aga Khan University. All the GPs in the list were visited at their clinics and those who consented to participate were interviewed. A GP was approached only once by the study team. If more than one GP was identified in a clinic, we interviewed all who agreed to participate. Additionally, if we identified a clinic which was not originally included in the list, we interviewed the GP(s) from this clinic as well.

A General Medical Practitioner was defined as a Bachelor of Medicine and Bachelor of Surgery degree holder practising medicine who does not hold a degree in any specialised medical specialty. The GINA 2009 guidelines were used to compare the practices of GPs with international standards. more than three of six questions correctly. Five questions had a single correct response and Question 6 had multiple responses, so only participants who gave correct answers to all parts of this question were deemed to have answered the question correctly; all other combinations were incorrect.

Adequate practice was defined as being able to answer more than three of six questions correctly.

Using Epilnfo Software, we calculated that, in order to estimate with $95 \%$ confidence the proportion of GPs with an adequate knowledge of asthma according to GINA guidelines assuming an expected frequency of $50 \%$ and a precision of $7 \%$, we needed to recruit 196 participants.

Based on cases of asthma regularly seen in clinics, a selfdesigned questionnaire was developed by the study group comprising GPs and Year 4 medical students of the Aga Khan University. The questionnaire was piloted on GPs working in the outpatient department of the Aga Khan University; no significant amendments were required to the questionnaire following the pilot study so that same questionnaire was used in the actual study. The questionnaire was used to obtain information on demographic data of practitioners such as age,
Adequate knowledge was defined as being able to answer

sex, time in practice, affiliation with other institutions, patients seen per day, regular reading of any journals, and whether they attended professional meetings. Four case scenarios were designed to extract responses on the management of asthma which were compared with the standard GINA 2009 guidelines for asthma management.

The questionnaires were completed by the GPs themselves in privacy and were collected by the study team later. All GPs taking part in the study were assured of complete confidentiality.

Ethical approval for the study was obtained from the ethics review committee of Aga Khan University and Hospital.

The data were double entered using Epi-data 6 software (World Health Organization and Centre of Disease Control, Stone Mountain, GA, USA) and validated to minimise data entry errors. The responses were then compared with the GINA guidelines. SPSS version 17.0 was used for all computer analyses.

Table 1. Sociodemographic characteristics of GPs

participating in the study

\begin{tabular}{|c|c|c|}
\hline Characteristics & $\begin{array}{l}\text { Number } \\
n=192\end{array}$ & Percentage \\
\hline \multicolumn{3}{|l|}{ Gender } \\
\hline Male & 116 & 60.4 \\
\hline Female & 76 & 39.6 \\
\hline \multicolumn{3}{|l|}{ Age } \\
\hline $25-29$ & 89 & 46.4 \\
\hline $30-34$ & 33 & 17.2 \\
\hline $35-39$ & 18 & 9.4 \\
\hline$>40$ & 52 & 27.1 \\
\hline \multicolumn{3}{|l|}{ Years of practice } \\
\hline $0-5$ & 93 & 48.4 \\
\hline $6-10$ & 40 & 20.8 \\
\hline $11-15$ & 21 & 10.9 \\
\hline$>15$ & 37 & 19.3 \\
\hline \multicolumn{3}{|l|}{ Affiliation (multiple responses) } \\
\hline Teaching hospital & 70 & 36.5 \\
\hline Private hospital & 78 & 40.6 \\
\hline Government hospital & 52 & 27.1 \\
\hline Only personal clinic & 36 & 18.8 \\
\hline Welfare/charity & 7 & 3.6 \\
\hline \multicolumn{3}{|l|}{ General patients in a day } \\
\hline$<10$ & 50 & 26.0 \\
\hline $10-20$ & 53 & 27.6 \\
\hline $21-30$ & 32 & 16.7 \\
\hline$>30$ & 57 & 29.7 \\
\hline \multicolumn{3}{|l|}{ Major sources of information } \\
\hline Professional training & 167 & 87 \\
\hline Colleagues & 24 & 12.5 \\
\hline Medical journals & 29 & 15.1 \\
\hline Professional meetings & 42 & 21.9 \\
\hline Medical representatives & 13 & 6.8 \\
\hline Print and electronic media & 14 & 7.3 \\
\hline \multicolumn{3}{|l|}{ Read medical journals on a regular basis } \\
\hline Do read medical journals & 89 & 46.4 \\
\hline Do not read medical journals & 103 & 53.6 \\
\hline \multicolumn{3}{|l|}{ Attend professional meetings } \\
\hline Do attend professional meetings & 153 & 79.7 \\
\hline Do not attend professional meetings & 37 & 19.3 \\
\hline
\end{tabular}




\begin{tabular}{|c|c|c|}
\hline Characteristics & Number $(n=192)$ & Percentage \\
\hline \multicolumn{3}{|c|}{ Fundamental pathological process in asthma } \\
\hline Adequate knowledge & 43 & 22.4 \\
\hline Inadequate knowledge & 149 & 77.6 \\
\hline \multicolumn{3}{|c|}{ Unusual history of a patient with asthma } \\
\hline Adequate knowledge & 153 & 79.7 \\
\hline Inadequate knowledge & 39 & 20.3 \\
\hline \multicolumn{3}{|c|}{ Management of asthma apart from medications } \\
\hline Adequate knowledge & 153 & 79.7 \\
\hline Inadequate knowledge & 39 & 20.3 \\
\hline \multicolumn{3}{|l|}{ Asthma medications } \\
\hline Adequate knowledge & 19 & 9.9 \\
\hline Inadequate knowledge & 173 & 90.1 \\
\hline \multicolumn{3}{|l|}{ Food exacerbates asthma } \\
\hline Adequate knowledge & 71 & 37.0 \\
\hline Inadequate knowledge & 121 & 63.0 \\
\hline \multicolumn{3}{|c|}{ Diagnosis other than asthma } \\
\hline Adequate knowledge & 78 & 40.6 \\
\hline Inadequate knowledge & 114 & 59.4 \\
\hline
\end{tabular}

\section{Results}

Of the 192 participants, 116 (60.4\%) were male. Most of the GPs $(53.7 \%)$ were aged $>29$ years and had been in practice for $>5$ years. Nearly all the GPs were affiliated with a teaching, private, or government hospital. Only 19\% of the GPs practised in their own clinic. When asked about their sources of information regarding asthma, 167 (87\%) said they relied on their professional training during medical school and internship. More than half of the GPs (53.6\%) did not read medical journals to update their knowledge; however, 79\% said that they attended professional meetings (Table 1 ).

Table 2 describes the knowledge of the GPs in relation to asthma. According to our study definition, only 43 GPs (22.4\%) had adequate knowledge of the fundamental pathological process in asthma. However, 153 (79.7\%) were able to identify correctly the symptoms not associated with asthma. Seventy-one GPs (37.0\%) knew that food does not exacerbate asthma, while only 19 (9.9\%) had adequate knowledge about the nature of asthma medications. For the management of asthma apart from medications, 153 (79.7\%) answered the questions correctly.

The responses to questions regarding practices of GPs for asthma diagnosis and management are described in Table 3. About half correctly managed well-controlled asthma $(n=97$, $50.5 \%$ ) and pregnant patients with asthma ( $n=102,53.1 \%$ ). However, only 27 (14.1\%) adequately managed acute exacerbations of asthma and 33 (17.2\%) offered correct advice to asthma patients wishing to exercise. Acute severe asthma was managed accurately by more than half of the GPs ( $n=113,58.9 \%)$.

GPs who were aged $>40$ years had less knowledge than younger GPS.

\section{Discussion}

Asthma is known to be a condition that causes significant morbidity worldwide and results in increased patient
Table 3. Practices in asthma by participating GPs

\begin{tabular}{|c|c|c|}
\hline Characteristics & Number $(n=192)$ & Percentage \\
\hline \multicolumn{3}{|c|}{ Asthma diagnosis (multiple responses) } \\
\hline Adequate practice & 190 & 99 \\
\hline Inadequate practice & 2 & 1.0 \\
\hline \multicolumn{3}{|c|}{ Advice for well-controlled asthma } \\
\hline Adequate practice & 97 & 50.5 \\
\hline Inadequate practice & 95 & 49.5 \\
\hline \multicolumn{3}{|c|}{ Advice for acute exacerbation } \\
\hline Adequate practice & 27 & 14.1 \\
\hline Inadequate practice & 165 & 85.9 \\
\hline \multicolumn{3}{|c|}{ Advice for asthma in pregnancy } \\
\hline Adequate practice & 102 & 53.1 \\
\hline Inadequate practice & 90 & 46.9 \\
\hline \multicolumn{3}{|c|}{ Management of acute severe asthma } \\
\hline Adequate practice & 113 & 58.9 \\
\hline Inadequate practice & 79 & 41.1 \\
\hline \multicolumn{3}{|c|}{ Advice for asthma patient who wishes to exercise } \\
\hline Adequate practice & 33 & 17.2 \\
\hline Inadequate practice & 159 & 82.8 \\
\hline
\end{tabular}

suffering, particularly in developing countries where socioeconomic factors, limited accessibility to high quality medical care, and poor environmental conditions adversely affect overall disease outcome. ${ }^{7,8}$ In addition, suboptimal management of asthma by GPs further aggravates the condition of patients and requires urgent attention in order to decrease morbidity worldwide. ${ }^{9}$

\section{Main findings and interpretation in relation to previously published work}

In our study only $28.6 \%$ of the GPs were found to have adequate knowledge regarding core concepts of asthma, and only $10.4 \%$ of GPs had adequate practice in asthma management. These results are consistent with those of Braido et al. who found that only $20 \%$ of the GPs included in their study were able to answer correctly the questions regarding asthma control. ${ }^{6}$ Our study shows that there is a strong need for urgent implementation of strategies to improve the knowledge of GPs regarding asthma concepts and to encourage standardised medical practices that are in accordance with an internationally accepted and regularly updated guideline.

In our sample almost $80 \%$ of the study participants were unaware of the fundamental pathology involved in asthma. These findings contrast with those of Braido et al., who found that almost $90 \%$ of the GPs were aware that chronic inflammation is responsible for the pathology underlying asthma, ${ }^{6}$ and thus reflects a poor understanding of the core concepts of asthma by GPs in our study. Surprisingly, $80 \%$ of the participants in our study knew that haemoptysis is a symptom not associated with a history of asthma, possibly because of the increased prevalence of pulmonary tuberculosis which usually presents with cough and haemoptysis together with other symptoms. They also knew the importance of avoiding allergens as an important part of managing asthma, in addition to asthma-related medications. This trend may be attributable to 
the fact that certain theoretical concepts had more practical application than others, such as typical and non-typical history, presentation, and risk factors that must be addressed (allergens).

However, knowledge of asthma medications in accordance with the GINA guidelines was found to be very inadequate with only $10 \%$ of the study participants able to identify correctly whether the pre-identified asthma medications used were relievers or controllers (or both). Also, almost $65 \%$ of the GPs considered food to be a source of asthma exacerbations. Such misconceptions have also been identified by various other studies, ${ }^{5}$ and highlight the need to hold regular sessions with GPs in order to improve their knowledge regarding asthma medications and to clear up such misconceptions.

Our study demonstrates that case presentations involving well-controlled asthma and asthma in pregnancy are relatively better managed than acute exacerbations. This may be because patients with acute exacerbations generally present to emergency staff and settings (i.e. hospitals) rather than to GPs. More than $80 \%$ of the GPs offered incorrect advice regarding asthma and exercise (77\% advocated exercise with inappropriate medicines and $5.7 \%$ no exercise at all). These results are a cause for concern. GPs may become the first point of access for patients who need immediate asthma care by virtue of being the 'closest doctor available' in an emergency situation. Advice may be sought from GPs regarding exercise by patients who do not have access to expensive specialist care or may not have the time to visit them. GPs should be aware of how to address such situations accurately in order to provide timely care and to prevent overmedication or negative lifestyle changes.

\section{Strengths and limitations of the study}

Our study had some limitations. The questionnaire used to collect the data from the study participants was self-administered and contained multiple responses that could be seen by the participants; as a result, correct responses could have been chosen by educated guesswork. Also, the standard for assessment was taken to be the GINA guidelines 2009, so our study tools were not sensitive for other guidelines that may or may not be adhered to with any consistency in our setting. The results of the study may differ slightly from actual practice since responding to questions is different from the practical aspect of practising medicine.

However, this study has a significantly greater sample size than previous similar studies in our setting and a more diverse study population as it involved most of the towns of Karachi including areas with different economic and social sectors. It therefore includes GPs treating a wide variety of patients across different socioeconomic and educational strata in a major urban city of Pakistan.

\section{Conclusions}

We conclude that, in this survey of 192 GPs in Karachi, there is an overall dearth of knowledge and inconsistency in practice demonstrated by GPs with regard to asthma control and management as recommended by international guidelines. Only about $50 \%$ of GPs can adequately manage common real-life case presentations in accordance with international guidelines. Surprisingly, only $14 \%$ of GPs were able to identify correct acute emergency presentations in asthma.

Association with teaching hospitals or regularly reading medical journals seems to have no effect, contrary to expectations. Future research efforts may need to explore the reasons for this apparent finding. Despite direct and indirect interventions such as Continuing Medical Education programmes and seminars, various misconceptions still prevail. Several of these misconceptions are the same as those identified in previous studies, so interventions need to be re-evaluated and made more effective so that these issues can be readdressed.

\section{Handling editor}

Hilary Pinnock

\section{Statistical review}

Gopal Netuveli

\section{Conflicts of interest}

The authors declare that they have no conflicts of interest in relation to this article.

\section{Contributorship}

NB: conception of idea and manuscript writing; SL, AA: questionnaire development; $Y$ J, UF, ZS, OH: data collection; WA, FB: data entry and analysis; SS: manuscript writing.

\section{Funding}

None.

\section{References}

1. United States Environmental Protection Agency. Asthma prevalence report on the environment database US EPA (last accessed 4 May 2011). http://cfpub.epa.gov/eroe/index.cfm?fuseaction=detail.viewind\&lv=list.listByAlpha\&r= 235294\&subtop=381

2. World Health Organization. Chronic respiratory diseases: asthma facts. Available at http://www.who.int/respiratory/asthma/scope/en/index.html (last accessed 11 March 2010).

3. Global Initiative for Asthma (GINA). The global burden of asthma report 2004 Available at http://www.ginasthma.org/reports-global-burden-of-asthma.html (last accessed 4 May 2011)

4. Kryj-Radziszewska E, Windak A, Margas G, Wizner B, Grodzicki T. The influence of guidelines of asthma management in adults in reference to family physician's knowledge in the field of treatment. Przegl Leg 2008;65(4):166-71.

5. Hussain SF, Zahid S, Khan JA, Haqqee R. Asthma management by general practitioners in Pakistan. Int J Tuberc Lung Dis 2004;8(4):414-17.

6. Braido F, Baiardini I, Stagi E, Piroddi MG, Balestracci S, Canonica GW. Unsatisfactory asthma control: astonishing evidence from general practitioners and respiratory medicine specialists. J Investig Allergol Clin Immunol 2010;20(1):9-12.

7. Morgan W, Crain E, Gruchalla R, et al. Results of a home-based environmental intervention among urban children with asthma. N Engl J Med 2004; 351(11):1068-80. http://dx.doi.org/10.1056/NEJMoa032097

8. Rosenstreich D, Eggleston P, Kattan M, et al. The role of cockroach allergy and exposure to cockroach allergen in causing morbidity among inner-city children with asthma. N Engl J Med 1997;336(19):1356-63. http://dx.doi.org/10.1056/ NEJM199705083361904

9. Ko FW, Chan AM, Chan HS, et al. Are Hong Kong doctors following the Global Initiative for Asthma guidelines: a questionnaire "Survey on Asthma Management". Hong Kong Med J 2010;16(2):86-93.

Available online at http://www.thepcrj.org 